\title{
economics-of-security.eu
}

Seo-Young Cho

\section{Integrating Equality - Globalization, Women's Rights, and Human Trafficking}

May 2012

Economics of Security Working Paper 69 
Correct citation: Cho, S.-Y. (2012). “Integrating Equality - Globalization, Women's Rights, and Human Trafficking". Economics of Security Working Paper 69, Berlin: Economics of Security.

First published in 2012

(C) Seo-Young Cho 2012

ISSN: 1868-0488

For further information, please contact:

Economics of Security, c/o Department of Development and Security, DIW Berlin - German Institute for Economic Research, Mohrenstr. 58, 10117 Berlin, Germany.

Tel: +49 (0)30 $89789-441$

Email: eusecon@diw.de

Website: www.economics-of-security.eu 


\title{
Integrating Equality
}

\section{- Globalization, Women's Rights, and Human Trafficking}

\author{
Seo-Young Cho*
}

May 2012

\begin{abstract}
This paper empirically investigates whether globalization can improve women's rights. Using panel data from 150 countries over the 1981-2008 period, I find that social globalization positively affects women's economic and social rights. When controlling for social globalization however, economic globalization does not have any effect on women's rights. Despite the positive effect of (social) globalization on women's standing in a country, (marginalized) foreign women, proxied with inflows of human trafficking, are not beneficiaries of such 'female-friendly' globalization effects.
\end{abstract}

Keywords: economic and social globalization; women's rights; human trafficking

Acknowledgement: The author would like to thank Axel Dreher, Stephan Klasen, Eric Neumayer, Niklas Potrafke, Krishna Chaitanya Vadlamannati, and Maria Ziegler for their helpful comments. The author cordially acknowledges the generous funding provided by the European Commission's Prevention of and Fight against Crime Action Grant (JLS/2009/ISEC/AAG/005).

* German Institute for Economic Research (DIW Berlin), Department of Development and Security, Mohrenstrasse 58, 10117 Berlin, Germany, Telephone: +49 (0)30 89789 307, Fax: +49 (0)30 89789 108, Email: scho@diw.de 


\section{Introduction}

The $21^{\text {st }}$ century epitomizes the era of globalization, witnessing massive exchanges of economic activities, human movements, and information flows across borders. Accordingly, globalization affects different dimensions of life, including women's standing and welfare. This paper investigates whether globalization could be a driving force in improving women's rights and if so, which type of globalization can be beneficial to women.

In an attempt to empirically investigate this question, much of the literature focuses on the effects of economic integration on women's economic activities. These studies look into the impact of globalization on women from the perspective of traditional trade theory, comparative advantage and competition, thus analyzing whether economic integration could create more employment opportunities for women and increase their wages.

This focus on economic integration and women's employment raises the question of how certain types of economic reform affect particular forms of women's rights and welfare. It is not surprising to observe very different outcomes across countries, depending on their economic and industrial structures. In other words, this approach focusing on economic globalization and female employment can provide the answer to the question of whether certain economic reforms could create an economic structure favorable to labor activities typically provided by women, and in addition, if such increases in demand could push up the price of female labor. However, it does not answer an arguably more fundamental question, that being whether globalization can eventually reduce the causes of gender discrimination, improve women's fundamental rights and generally empower women.

To address this issue, one should look beyond the impact of globalization on women's economic activities - wages and employment - and examine whether globalization can enhance 'women's status' or 'women's rights', which allow women better access to resources and ensure their standing in legal and social institutions without discrimination (Morrisson and Jütting 2005). Surprisingly, most of the present literature has neglected the difference between women's rights and the subsequent outcomes, merely investigating the impact of globalization on certain economic activities of women. To the best of my knowledge, there are only a few existing studies empirically addressing the causal relation between women's fundamental rights and globalization. Among them, Neumayer and de Soysa $(2007,2011)$ and Richards and Gelleny (2007) show that economic globalization positively affects women's rights. However, these studies limit globalization to economic integration, which tends to be 
more closely associated to the outcomes of women's economic activities rather than the fundamental rights of women, and do not take into account the impact of another important dimension of globalization, social globalization. Social globalization - defined as information flows, personal contacts, and cultural sharing across countries (Dreher 2006) - can arguably be a more important determinant of women's rights because it can promote the spread of ideas, norms and civil actions worldwide by facilitating contact and communication across people in different countries (Rosenau 2003).

In this respect, Gray et al. (2006)'s study is worthwhile noting here. Their study focuses on the diffusion of women's rights through international interconnectedness. International interconnectedness includes not only trade openness and FDI but also commitments to the international organizations such as the ratification of the Convention on the Elimination of All Forms of Discrimination Against Women (CEDAW), capturing political and social interaction across countries ${ }^{1}$. They find that commitments to CEDAW are an important driving force of diffusing gender equality worldwide. However, their analysis does not include personal interactions and communications among people of different cultural backgrounds as part of social globalization. Arguably, such multicultural contacts at the personal level can influence people's exposure to new ideas, values, and norms more directly than integration at the country level. In addition to Gray et al., a recent study by Potrafke and Ursprung (2012) poses a similar question, addressing that both social and economic dimensions of globalization are positively associated with women's institutional rights. However, their study investigates the impact of economic and social globalization separately, not taking into account that there might be overlapping effects between the two. In other words, it could be possible that the positive effects of economic globalization have been detected because of the underlying effects of social globalization which accompany the ${ }^{2}$. In fact, despite positive correlation, economic and social globalization represents different dimensions of international exchanges, with potentially very different goals. While economic globalization mainly reflects the flows of goods and services for the interests of capital, social globalization connects people and enables them to exchange ideas and information, furthermore pursuing solidarity in shared causes (e.g. human rights and gender equality).

\footnotetext{
${ }^{1}$ Sweeney $(2006,2007)$ also investigates the effects of CEDAW and democracy on the spread of women's rights attainment - in particular economic rights.

${ }^{2}$ Additionally, their study is limited to cross-sectional data in developing countries, not capturing variations in women's rights over time worldwide.
} 
Building on the current literature, my paper investigates the potential effects of social globalization on women's rights. As said earlier, people living in countries with a high level of social globalization are more likely to express and respect opinions different from tradition and conventional thinking, as well as demonstrating increased cohesion in shared causes for change (Rosenau 2003). In this respect, social globalization could lead to societal tolerance and acceptance for progress in women's rights and their alternative roles. The result of the test presented in appendix 1 empirically backs up Rosenau's argument. The empirical finding shows that social globalization enhances the level of civil liberty - defined as the freedom of expression and civil association - enabling social reform which can be transmitted into the betterment of women's rights ${ }^{3}$. Such positive effects of social globalization would affect overall human rights practices, however, the impact can arguably be stronger for women. This is because women would not lose but rather benefit through changes challenging the established male-dominated societal structures social globalization may bring.

My investigation makes the following contributions to the literature. First, this paper addresses and empirically investigates the importance of social globalization on women's rights and singles out the effects of social globalization separately from those of economic globalization. Second, my analysis includes not only rights of female citizens in a country, but is extended to examine whether the impact of social globalization, if any, can also reach foreign women illegally living in other countries whose rights are presumably marginalized in the legal system. Here, human trafficking is proxied as an indicator of how a country tolerates abuse and exploitation of these women. This proxy is suitable as human trafficking is a form of extreme exploitation, usually for sexual and labor purposes, and the vast majority of victims are foreign women (UNODC 2006). This paper argues that if globalization can promote respect for women's rights, making them norms across countries, then such an improvement should benefit not only local women, but also foreign women living in another country. Addressing human trafficking in relation to the impact of globalization on women's rights is a new approach and, to the best of my knowledge, this paper is the first study dealing with this issue.

Through a cross-country analysis of 150 countries during the 1981-2008 period, I find that: 1) social globalization increases women's rights; 2) the impact of economic globalization

\footnotetext{
${ }^{3}$ On the other hand, the empirical findings indicate there is no significant effect of economic globalization on civil liberty. Furthermore, neither social nor economic globalization affects the level of the rule of law, another potential candidate for transmission (appendix 1). It seems that globalization influences women's rights via changes in civil actions rather than law itself.
} 
disappears when controlling for social globalization; and 3) despite the positive linkage between globalization and women's rights, globalization does not have any positive effect on foreign women's rights, proxied with human trafficking.

This paper continues as follows. Section 2 presents the main hypotheses. Section 3 describes the data on women's rights and globalization, as well as human trafficking. Section 4 discusses the estimation strategy including endogeneity concerns, followed by the empirical findings in section 5 and tests for robustness in section 6 . In section 7, this paper concludes with policy implications.

\section{Hypotheses}

\subsection{Economic Globalization and Women's Rights}

A considerable amount of literature has contributed to the question whether economic globalization improves women's economic rights in the form of employment and wages. Proponents of globalization argue that trade and FDI positively affect women's employment opportunities in developing countries, due to their comparative advantages. In other words, developing countries have a comparative advantage in labor-intensive goods, thus demand for female labor would increase in order to keep price competitiveness in international trade as female wages are generally lower. Indeed, many empirical studies find a positive association between export-oriented manufacturing and women's increased share in paid employment (Chow 2003; Fontana and Wood 2000).

However, an increase in female labor force participation does not always lead to economic empowerment as long as such demand for female labor is based on women's acceptance of poor payment and exploitative working conditions. Although StolperSamuelson-type trade theory predicts that an increase in demand for female labor will eventually lead to higher female wages and better working conditions, empirical evidence does not necessarily support this theoretical prediction as long as there is an abundance of unemployed workers available in those developing countries. The literature clearly suggests contradicting results. On the one hand, globalization may benefit women in general by reducing gender differences in employment and wages if accompanied with subsequent economic growth due to the relatively flexible accommodation of females into the labor forces of integrated economies (Tzannatos 1999). On the other hand, export- led growth, based on ever-growing competition and price cuts, may increase the divide between the winners and 
losers of globalization, which could negatively affect women's welfare given women's vulnerability in society (Berik 2000). Furthermore, even if economic globalization decreases gender differences in labor markets, such a reduction may not necessarily indicate women's empowerment because it may be the case that gender gaps were narrowed due to the disproportional deterioration of (a previously high level of) male wages and working conditions (Berik 2000). While disagreeing on the potential impact of economic integration, both arguments seem to unanimously conclude that additional efforts such as the promotion of female education and reduction of feminized poverty are required in order for economic integration to generate a positive impact on women's empowerment.

Building on such arguments, I predict that economic globalization itself is not a driving force in improving women's economic rights because the interests of global capital are not necessarily to empower women but rather likely to utilize their labor forces in order to maximize competition (Sen 2001; Cağatay and Ertürk 2004). In this paper, an inclusive term, women's economic rights, is used. Neither female wage nor employment reflects the overall economic empowerment of women as it is often the case that female employment increases due to low wages. Thus, I utilize a composite measurement of women's economic rights, that being access to economic resources - including women's pay, employment and entrepreneurship - in order to estimate the overall effect on women's economic status ${ }^{4}$.

Moreover, I expect that economic globalization will not improve women's social and political rights ensuring gender equality in private and public spheres. As mentioned above, a potential increase in female participation in economic activities is generated by capitalists' need for cheaper labor (Sen 2001), which may not lead to an improvement in women's fundamental rights, especially if a women's role is merely seen as a provider of cheap labor or a supplement to male labor. This type of globalization may set women's role in the society as inferior to the male role and therefore women's rights beyond the scope of employment would not be improved. With this argument, I predict that economic globalization does not increase women's rights in the social, political, and institutional dimensions as these rights are not directly related to the interests or needs of the market.

\section{H1. Economic globalization does not increase women's rights}

\footnotetext{
${ }^{4}$ I will discuss this measurement in more detail in section 3.
} 


\subsection{Social Globalization and Women's Rights}

A commonly accepted definition of globalization includes not only economic, but also political, cultural, social, and technological interactions across countries (Dreher 2006). In other words, globalization also represents the spread of ideas, information, values and people, going beyond the flow of goods, capital and services or market exchanges.

While critics of a Washington Consensus type of globalization argue that neo-liberal economic integration may exacerbate poverty and inequality by intensifying competition (Cagatay and Ertürk 2004), scholars focusing on global diffusion of norms suggest that social globalization should be a mechanism for promoting norms, values of democracy, human rights and 'learning processes' through information exchanges and personal interactions (Chow 2003; Elkins and Simmons 2005).

Social globalization provides people with more opportunities to communicate and form networks each other and therefore increases freedom of expression and civil association making social progress and changes more feasible, as mentioned earlier. This linkage suggests a possible mechanism for transmitting the effects from social globalization to women's rights. For instance, advanced telecommunications can enable advocates of women's rights to cooperate and form civil associations to gether to pursue common agendas, as seen through the recent public campaigns against the execution of an Iranian woman by stoning for committing adultery ${ }^{5}$. This is achieved through actively utilizing online discussions and petitions which are organized by international human rights and women's rights groups. Also, with the development of the internet and other telecommunication technologies, news about abuse and unequal treatment of women can spread quickly and provoke public attention in other countries, which can place international pressure on countries where gender inequality is high. Moreover, increases in information exchanges can create opportunities for people to learn about positive representations and roles women carry out in more developed countries, generating 'learning effects' (Simmons and Elkins 2004).

Besides interaction through communication devices, social globalization also promotes direct personal contact among people from different countries in the form of immigration and tourism. Personal interaction among different people can have a positive impact on tolerance towards different lifestyles and increase acceptance of different gender roles, sexuality, religions and ethnic backgrounds (Rosenau 2003). This has the potential to

\footnotetext{
${ }^{5}$ July $2^{\text {nd }}, 2010$, Guardian. http://www.guardian.co.uk/world/2010/jul/02/iranian-wo man-stoning-death-penalty
} 
enable changes in women's role in society. Furthermore, social globalization tends to decrease cultural gaps across countries because people are now more exposed to different cultures. As women's rights are deeply grounded in culture and value systems (Simmons 2009), cultural exposure to, and proximity with other diverse cultures can have a positive impact in reducing discriminatory cultural practices against women.

Social globalization can therefore create change in the perceptions and attitudes towards women and thus the impact of social globalization on women's rights is arguably stronger than that of economic globalization. In particular, social globalization will have a positive impact on women's social rights, granting equality in family matters and selfgovernance because these rights directly reflect societal perceptions and attitudes towards women.

\section{H2: Social globalization increases women's rights.}

\subsection{Globalization and Rights of Marginalized Foreign Women}

One important question this paper contributes to the literature is whether globalization can be further beneficial to women without a legal standing in a country. Human rights protection is basically a matter for sovereign nations and their own citizens (Poe, Tate and Keith 1999), even in the era of globalization. When countries protect the rights of citizens of another country, it is mainly due to pressure and intervention from the country where the citizens hold their nationality. While countries may have interests in empowering their own female citizens, they do not necessarily have much incentive to ensure the rights of foreign women, particularly those without a legal standing in the country. Those women - illegal female migrants - are generally marginalized from receiving rights protection in the country of residence due to double-constraints: being foreign and illegal migrants. In this paper, I try to find out whether globalization - economic and social - can reverse this trend and have a positive impact in this area, regardless of citizenship.

This is in fact a tricky question as although globalization may improve domestic women's rights, this empowerment may not have the same impact on foreign women and it may even generate a negative impact. For instance, let's assume that a country improves women's rights and domestic women no longer want to work in exploitative sex industries as prostitutes because they can find other opportunities. However, if there is still a need for these services domestically (as men continue to demand them), it may lead to the illegal immigration of women from poorer countries who are more likely to tolerate exploitative 
situations. In fact, when analyzing the statistics regarding international female trafficking for sexual exploitation, the major destinations are mostly developed countries where women generally enjoy high levels of rights (UNODC 2006).

Having said that, flows and exchanges of goods and services, usually accompanying human movements, may facilitate such illicit human transactions which can be used to fulfill the demand for cheap (and exploitative) sexual and labor services trafficking victims can provide (Mahmoud and Trebesch 2010). Moreover, if economic globalization can provide more employment opportunities for domestic women, as seen in many developing countries, the domestic supply of jobs likely to be of exploitative nature - such as prostitution and domestic servant work - would decline. The lack of such supply may induce more human trafficking flows as victims of human trafficking could be forced into doing such work. On the other hand, if globalization - in particular social globalization -improves general respect for women, it could also lead to the assurance of foreign women's rights, reducing exploitation against them. By proxying the rights of and respect for marginalized foreign women with inflows of international human trafficking I construct two further hypotheses:

\section{H3. Economic globalization increases human trafficking.}

\section{H4. Social globalization reduces human trafficking.}

\section{Measuring Globalization and Women's Rights}

\subsection{Globalization}

In this paper, economic globalization captures two actual economic flows: trade openness (the ratio of imports and exports to GDP) and foreign direct investment (accumulated stock ofFDI normalized by GDP) ${ }^{6}$. FDI stocks are taken instead of flows because stocks reflect the longterm influence of multinational corporations in a country. Trade openness and FDI are the most commonly used indicators of economic globalization (Berik et al. 2004; Gray et al. 2006; Fontana and Wood 2000; Neumayer and de Soysa 2007, 2011: Oostendorp 2009; de Soysa and Vadlamannati 2011, among many others).

\footnotetext{
${ }^{6}$ I employ the two indicators of economic globalization instead of the KOF Economic Globalization Index because there is no convincing theoretical linkage suggesting a direct effect of restrictions on trade and capital flows on wo men's rights. If there is any effect, it should be an indirect effect via trade and FDI. A lso, by using an individual indicator, problems caused by aggregate measurements can be avoided.
} 
For the purpose of defining social globalization, this paper employs the KOF Index (Dreher 2006). The KOF Index classifies social globalization in three sub-dimensions: personal contacts, information flows and cultural proximity ${ }^{7}$. The 'personal contacts' dimension captures direct interaction among people across countries. It includes international telecom traffic, international letters sent and received, arrival/departure of international tourists, government and workers' transfer received and paid (as a percentage of GDP) and stocks of foreign population living in a country. The first two indicators measure direct communications among people living in different countries, while the latter three ind icate the degree of face-to-face interaction with foreigners. The 'information flows' dimension is intended to proxy potential flows of ideas and images. This dimension includes the number of internet users, cable television subscribers, and the number of radios and daily newspapers traded. These indicators measure (potential) the degree of news and information exchanges and the spread of ideas, images and norms. The last dimension is 'cultural proximity', capturing familiarity with the Western cultures - arguably the most influential cultures worldwide in our time (Dreher 2006). It includes the number of McDonald's outlets and IKEA stores, as well as the amount of books imported and exported (as a percentage of GDP). Given the fact that books are generally cultural goods, book trade proxies cultural exchanges, while newspaper trade stands for information exchanges.

\subsection{Women's Rights}

To measure women's rights, I make use of the composite index developed by Cingranelli and Richards (CIRI) Human Rights Dataset (2008). The CIRI index provides three indicators to represent women's economic, political, and social rights, respectively. The main advantage of using the CIRI index is that this data captures comprehensive dimensions of women's standing by law and in practice. Furthermore, the dataset the CIRI Index provides covers up to 190 countries for the last three decades enabling to ascertain global patterns in women's rights attainment $^{8}$.

\footnotetext{
${ }^{7}$ In this paper, I make use of each sub-dimension of the Social Globalization Index instead of employing the overall index in order to capture the specific aspects each dimension reflects, and also to avoid problems caused by aggregate measurements.

${ }^{8}$ Although the CIRI Index is comprehensive, global indicators serving the purpose of my research, it is not free of limitations. One important limitation is that these indicators are aggregated ordinal point scales loosing detailed information on complex factors of women's economic, political, social rights. As a result, it is difficult to see which components of each right are being realized and which are not being respected in law and practice towards the respective right - i.e. improvement in the women's economic rights indicator could be caused by many different factors such as equal payment, equality in hiring and promotion, etc. The same issue arises with the women's social rights indicator. A same score can be driven by many different combinations of wo men's social rights attainments and it is hard to tell which components of women's social rights improved while others
} 
The women's economic rights index includes women's rights for equal pay for equal work, free choice of profession, the right to gainful employment, equality in hiring and promotion practice, job security, non-discrimination by employers, the right to be free from sexual harassment at workplaces, the right to work at night, the right to take dangerous work and the right to work in the military and the police force. The women's social rights index captures the right to equal inheritance and equal marriage, the right to travel abroad and obtain a passport, the right to confer citizenship to children or a husband, the right to initiate a divorce, the right to property brought into marriage, the right to participate in social activities, as well as education, the freedom to choose a residence, and freedom from female genital mutilation and forced sterilization. The women's political rights index represents the right to vote and run for political office, the right to hold government positions and join political parties, and the right to petition government officials.

\section{2. 1. Human Trafficking}

Human trafficking inflows into a country are a proxy for the respect for foreign women without a legal standing which exists in that said country. It is a good indicator for this purpose because human trafficking is an extreme form of abuse and violence against those vulnerable in society, the vast majority of victims being foreign women (UNODC 2006). Therefore, this proxy indicates whether women's rights can be ensured regardless of citizenship and for those most marginalized in society.

As human trafficking is a clandestine, criminal activity, with those being trafficked and involved in such activities being part of 'hidden populations' (Tyldum and Brunovskis 2005), reliable and comparable data reflecting the comprehensive magnitude of the problem is very difficult, if not impossible, to obtain (Kangaspunta 2003). Among the currently available sources, the Incidence Reporting Index developed by the UNODC (2006) is arguably one of the most reliable and comprehensive indicators ${ }^{9}$. This index aggregates numbers of human trafficking incidences recoded by 113 major institutes worldwide during the data collection

remain the same or even declined. In other word, with these uni-dimensional scales of the CIRI Index, we are unable to distinguish variations in the levels of respect for different types of women's rights. Additionally, the composition of the women's economic indicator focuses on women's rights in employment and workplaces while neglecting several other important economic rights such as subsistence rights (the rights to adequate food, clothing and housing) and other rights to ensure women's well-being, widely because of the lack of internationally comparable statistics. The author thanks an anonymous referee for pointing out these issues.

${ }^{9}$ Given that human trafficking is as sociated with migration (Mahmoud and Trebesch 2010), migration data could be an alternative measurement. However, correlation between the UNODC human trafficking data and international migration rates (taken from the United Nations Population Fund 2008) is just 0.34. This low correlation is possibly driven by the fact that the existing migration data mainly reflect legal, documented migration, while human trafficking is more closely associated with illegal migration. 
period of 1996-2003, covering 161 countries, i.e. by using reports published by these institutes, the UNODC identified and counted the number of human trafficking cases for each country. The Index has an ordinal scale ranging from 0 to 5 , with 0 indicating no (reported) inflow of human trafficking and 5 a very high inflow (see figure 1). The composition of the Index shows that the majority of the incidences are clearly related to female trafficking. $77 \%$ of the incidences are categorized as sexual exploitation while forced labor including domestic servitude and other slavery work takes $23 \%$. The majority of victims are women $(54 \%)$ and girls $(17 \%)$ - mostly illegal migrants ${ }^{10}$. This index has been employed for several empirical studies on human trafficking (Cho 2012; Cho and Vadlamannati 2012; Jakobsson and Kotsadam 2011).

On the other hand, this index is not free from drawbacks. First, the Index partially relies on self-reporting by countries because $27 \%$ of the informational sources come from governments. Using governmental sources may bias the measurement because of different levels of law enforcement and different data collection methods and definitions of human trafficking used across countries, making international comparison difficult ${ }^{11}$. However, the UNODC also utilizes various other informational sources: international organizations (32\%), NGOs (18\%), research institutes (18\%), and media (5\%). Given that, potential biases causes by self-reporting are arguably lower in the UNODC index, compared to other available official statistics (such as national crime statistics), which are completely dependent on selfreporting by governments. Furthermore, the data was coded from the aforementioned reports by the UNODC (not by individual governments) based on the international definition of human trafficking prescribed by the UN Anti-trafficking Protocol (2000), further mitigating problems in international comparison.

In addition to self-reporting, there are some other drawbacks of the Index. It aggregates information collected during the period and therefore time-variations of human trafficking are not captured. Moreover, given the geographical distribution of informational sources, the data collection can be subject to regional bias, namely an overestimation of

\footnotetext{
${ }^{10}$ Some of the victims recoded in the Index are not females - boys $(3 \%)$, men $(2 \%)$, and children without mentioning the sex (24\%). Therefore this index represents male trafficking as well to a certain degree, although they are a minority.

${ }^{11}$ There is another concern that human trafficking may not be illegal in some countries and therefore human trafficking incidences in these countries may not be captured in the Index. However, the Anti-trafficking Policy Index (Cho at el. 2011) shows that to present, 148 countries wo rld wide have already adopted anti-trafficking law, indicating that the majority of the world have acknowledged the illegality of human trafficking in their national law. However, it is still possible that incidences - particularly those reported in governmental sources - may not have thoroughly been collected in countries where national legislation against human trafficking is absent or the law is not enforced.
} 
incidences in Western countries and an underestimation in other regions. ${ }^{12}$ In order to overcome these problems, I employ another dataset coded from the United States Trafficking in Persons Reports (2001-2009). Country narratives of the reports categorize countries of destination if at least 100 cases of human trafficking inflows have been discovered in the past year. I construct a binary variable that is equal to 1 if a country is a destination in a given year and 0 otherwise, following Akee et al. (2010a, 2010b). This binary panel data with time variations supplements the UNODC Index with cross-sectional, but more detailed ordinal scores.

\section{Estimation Strategies}

For the analysis on women's rights, I estimate pooled time-series cross-section (panel data) regressions. The panel data cover a maximum of 150 countries during the 1981-2008 period. The basic equation to test the hypotheses is specified as:

$$
\text { Rights }_{\text {it }}=\alpha_{1}+\beta_{2} \text { Rights }_{i t-1}+\theta_{3} \text { Globalization }_{\text {it }}+\varphi_{4} \mathrm{Z}_{\mathrm{it}}+v_{\mathrm{t}}+\mathrm{u}_{\mathrm{it}}
$$

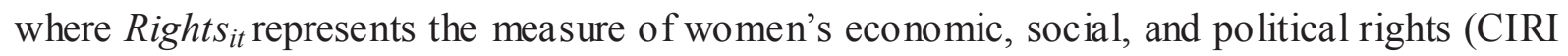
Index) respectively, for country $\mathrm{i}$ in year t. Globalization ${ }_{i t}$ is the main variable(s) of interest: trade openness and FDI for economic globalization and information flows, personal contacts and cultural proximity for social globalization. $\mathrm{Z}$ is a vector containing control variables. $v_{\mathrm{t}}$ time fixed effects and $u_{i t}$ is the idiosyncratic error term. This model also includes the lagged dependent variable, Rights it- $_{\text {, }}$, as women's rights reflect culturally rooted practice and persist over time (Cho 2010). Including a lagged dependent variable has another advantage, that being it fixes problems associated with autocorrelation and model dynamic effects of $\mathrm{X}$ variables on Y (Beck and Katz 1995). The dependent variable has an ordinal structure ranging from 0 to $3^{13}$, therefore I estimate the model with ordered probit.

Consequently, country fixed effects cannot be controlled for due to the incidental parameter problem (Wooldridge 2002). Instead, this model includes several time-invariant variables which reflect country characteristics and influence women's rights in that country.

\footnotetext{
${ }^{12}$ The geographical distributions of the informational source institutions are Western Europe (29\%); North America (18\%); Asia (11\%); Africa (5\%); Central and Eastern Europe (5\%); Lat in A merica (4\%); Oceania (4\%); and the CIS ( $2 \%)$, in addition to $22 \%$ of institutions categorized as international.

${ }^{13}$ Each of the CIRI indices has an ordinal score ranging from 0 to 3 : score 0 indicating no wo men's rights in the relevant dimension; 1 some women's rights guaranteed under law but not enforced in practice; 2 some rights guaranteed under law and enforced in practice but still allowing a low level of discrimination against wo men; and 3 full or nearly full rights guaranteed by law and enforced in practice (for further information on the Index, see Cingranelli and Richards 2008).
} 
In this regard, regional effects are controlled for because there are significant regional differences in regard to social institutions and practices dealing with women's rights (Morrison and Jütting 2005). The percentage of the total population which is Muslim in a country - taken from Encyclopedia Britannica Book of the Year (2001) - is also included because women's rights are closely associated with religion (Dollar and Gatti 1999) and Islamic practice is known to be negatively related to women's rights (Ross 2008). Standard errors are clustered at the country level to account for the fact that observations from the same country in different years are not independent observations.

The vector of control variables $\left(Z_{i t}\right)$ includes other potential determinants of women's rights suggested by the previous literature on the subject. I follow the studies of Gray et al. (2006), Potrafke and Ursprung (2012), Neumayer and de Soysa (2007, 2011) and Oostendorp (2009), who all focus on causal factors of women's rights and gender discrimination. Accordingly, the model includes the level of economic development, (logged) per capita income, with data taken from the World Development Indicators (2009), as well as political development, democracy, with data taken from the Polity IV data (Marshall and Jaggers 2009). Additionally, this model includes the level of civil liberty (Freedom House 2009) ${ }^{14}$ because freedom of expression and civil association can be a driving force of social change, including an improvement in women's rights. As seen in appendix 1, social globalization enhances civil liberty by providing more opportunities for civil associations and communications and civil liberty is therefore suggested as a transmission mechanism from social globalization to women's rights. I estimate the model both with and without the civil liberty variable in order to find out whether social globalization generates additional effects on women's rights beyond its impact on civil liberty - the human rights of all citizens which are also positively associated with women's rights.

Turning to the estimation with human trafficking, the model takes the following form:

$$
\begin{aligned}
& \text { HumanTrafficking }_{\mathrm{i}}=\alpha_{1}+\theta_{2} \text { Globalization }_{\mathrm{i}}+\varphi_{3} Z_{\mathrm{i}}+\mathrm{u}_{\mathrm{i}} \\
& \text { HumanTrafficking }_{\mathrm{it}}=\beta_{1}+\rho_{2} \text { Globalization }_{\mathrm{it}}+\omega_{3} \mathrm{Z}_{\mathrm{it}}+\mu_{\mathrm{i}}+v_{\mathrm{t}}+\mathrm{u}_{\mathrm{it}}
\end{aligned}
$$

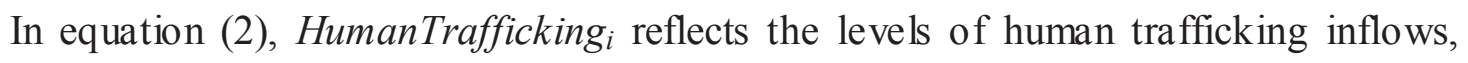
taken from the UNODC Index, and Globalization is $_{i}$ the main variable(s) of interest. I use

\footnotetext{
${ }^{14}$ The in itial value of the Freedom House Civil Liberty Index has a seven-point scale: 1 having the highest value and 7 the lowest one. In this paper, I inverse the values, i.e. score 7 being the highest value and score 1 the lowest.
} 
values of the explanatory variables prior to the UNODC data collection period of 1996-2003 (from the periods of 1981-1995 and 1995, respectively) in order to avoid reverse-feedback effects. $Z_{i}$ is a vector containing control variables and $u_{i}$ is the idiosyncratic error term. As the dependent variable has an ordinal structure ranging from 0 to 5, I employ an ordered probit estimation and cluster standard errors at the country level. Additionally, I conduct a panel analysis covering the years 2000-2008 by using panel data coded from the United States Trafficking in Persons Annual Reports (2001-2009). The specification is shown in equation (2'). HumanTrafficking ${ }_{i t}$ is a dummy variable, with 1 indicating a country that had more than

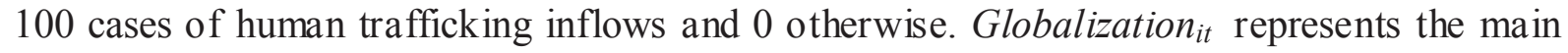
variable(s) of interest. $Z_{i t}$ is a vector containing control variables. $\mu_{\mathrm{i}}$ represents (time- invariant) unobserved individual heterogeneity and $v_{t}$ captures time-fixed effects. $u_{i}$ is the idiosyncratic error term. Given the dependent variable is a dummy, I employ probit estimations and cluster standard errors at the country level. Additionally, probit random effects estimations are conducted in order to control for unobserved heterogeneous effects.

For the selection of control variables, I follow the literature focusing on pull factors of human trafficking (Akee et al. 2010 a, b; Cho 2012; Cho et al. 2012). First, the model includes (logged) per capita income as income is seen as a dominant factor pulling human trafficking. As human trafficking is largely operated by organized criminal groups, the level of (control of) corruption that affects organized criminal activities, data taken from Kaufmann et al. 2009, is also controlled for. (Domestic) women's rights are included because human trafficking is a gender-based problem, with women making up the majority of victims (UNODC 2006). (Logged) population sizes are also controlled for in order to normalize human trafficking incidences by population sizes. Additionally, the model controls for regional effects.

\subsection{Endogeneity Concern}

This section addresses whether the main model - equation (1) - is subject to reverse feedback effects, i.e. improvements in women's rights are causes of global integration rather than outcomes. Arguably, greater women's rights might also lead to higher levels of globalization. For example, the active participation of women in society may increase information and personal exchanges across countries because there will be a larger pool of internet users, travelers etc. Table 1 shows the results of the Granger causality tests which were conducted to address this issue. According to Granger (1969), a variable $\mathrm{x}$ is Granger-causing a variable y 
if past values of $\mathrm{x}$ helps to explain $\mathrm{y}$, once the past influence of $\mathrm{y}$ has been accounted for. I follow Dreher et al. (2011) to address Granger causality in a panel setting as:

$$
y_{i t}=\sum_{j=1}^{\rho} \psi_{j} y_{i t-j}+\sum_{j=1}^{\rho} \xi_{j} x_{i t-j}+\delta_{i}+\zeta_{t}+\omega_{i t}
$$

Where $\mathrm{i}=1, \ldots, \mathrm{N}$ and $\mathrm{t}=1, \ldots \mathrm{T}$. The parameters are denoted by $\psi_{\mathrm{j}}$ and $\xi_{\mathrm{j}}$ and the maximum lag length is represented by $p . y_{i t}$ represents the level of globalization for country i during the year t, while $x_{i t}$ represents women's rights. While $\delta_{\mathrm{i}}$ represents unobserved individual effects, $\zeta_{\mathrm{t}}$ is the unobserved time effects. $\omega_{\text {it }}$ denotes the idiosyncratic error term ${ }^{15}$. As the time period of the panel is 28 years, this is sufficiently long for the tests (Hamilton 1994). The optimal number of lags to be included is determined by $\mathrm{Ng}$ and Perron's (1995) sequential t-test on the highest order lag coefficient, with a lag length of one being appropriate. To test whether women's rights Granger-cause globalization, I check for the joint significance using an F-test. The results are shown in table 1. The null hypothesis to be tested is that women's rights do not Granger-cause globalization. The second column in table 1 indicates that two variables of social globalization are Granger-caused by women's rights: information flows by women's economic rights and personal contacts by both women's economic and social rights, as one fails to reject $\mathrm{H}_{0}$. On the other hand, women's rights do not Granger-cause Trade, FDI, and Cultural Proximity. When testing for the Granger-causality driven from globalization to women's rights (shown in the third column), all of the three social globalization indicators Granger-cause women's rights, while the Granger-causal effects of economic globalization are somewhat mixed, i.e. economic globalization affects women's economic rights but there is no evidence suggesting that trade affects women's social, political rights.

The results indicate that globalization is essentially the cause of women's rights. For information flows (to women's economic rights) and personal contacts (to both economic and social rights), reverse effects running from women's rights to globalization are also detected. In order to address the endogeneity of these two variables, an instrumental variable (IV) approach is employed. The estimation methods are a two-stage least square technique with two-way fixed effects (2SLS) and an instrumental variable ordered probit (oprobit IV). Given the ordinal structure of the dependent variables, the oprobit IV estimation is more efficient

\footnotetext{
${ }^{15}$ As the Granger causality tests rely on the assumption that the series are stationary, I test the null hypothes is that all series are non-stationary by employing the unit root test proposed by Maddala and Wu (1999) for (unbalanced) panel data. Based on the p-values of the ind ividual unit root tests, the overall Maddala and Wu test statistic is calculated. The hypothesis of a unit root is rejected at the $1 \%$ level.
} 
than 2SLS (Long 1997), while 2SLS estimations have the advantages of controlling for unobserved individual heterogeneity. Thus, I employ both methods and compare the results.

Knowing that it is difficult to find a single instrument with a high explanatory power for globalization but no direct effect on women's rights, I combine the three variables which seem to be most relevant as the instruments. First is the level of restrictions to trade and capital flows. It is closely associated with information flows and personal contacts because such restrictions are obstacles to receiving information, as well as human flows (particularly foreign employees working on foreign operations) from other countries. Restrictions to trade and capital flows would not have a direct link to women's rights, as can be seen from the results in table 2 that economic globalization does not have any explanatory power on women's rights, particularly controlling for social globalization, supporting the exclusion restriction criteria ${ }^{16}$. Another instrument is the number of McDonald's outlets in a country, which reflects cultural openness to the Western cultures, an indicator of social globalization ${ }^{17}$. Having more McDonald's outlets in a country would not directly improve women's rights however. The other instrument is "voting in line with G-7 countries in the UN General Assembly on key issues', suggested by Dreher and Sturm (2012) ${ }^{18}$. The justification for the selection of this instrument is that countries sharing political similarities with the major powers are likely to exchange information and people with those countries which are also major senders of information and human flows, while this instrument is arguably not a direct determinant of women's rights.

Table 3 shows the validity of the instruments in terms of relevance and exclusion criteria. First, instrument relevance determines whether the selected instrument has a strong explanatory power on the endogenous explanatory variable of interest. The Cragg-Donald's first-stage F-test (Cragg and Donald 1993; Stock et al. 2002) is used to test for the relevance. This test reports the statistic used to test the null hypothesis, i.e. whether the parameter estimate for the instrument in the first stage regression is equal to zero. A Cragg-Donald's

\footnotetext{
${ }^{16}$ Furthermore, when I regress wo men's rights on the restriction variable, the coefficients of the restrictions tum to be insignificant. However, acknowledging that the restriction variable can be a direct measurement of economic globalization, whose effect is being investigated in my paper, I run an additional IV estimation using the other instruments (UN voting and McDonald's outlets) only, o mitting the restriction variable, and the results do not alter the main findings.

${ }^{17}$ The number of McDonald's outlets is part of cultural proximity, which turns out to have no exp lanatory power for wo men's rights in the empirical testing (see table 2). In the process of running IV regressions, when I include the number of McDonald's outlets variable in the first stage regression, I exclude the cultural proximity variable in the second stage.

${ }^{18}$ I take the voting behavior index based on the definition of Thacker (1999), who codes votes in agreement with the United States as 1 , votes in disagreement as 0 , and abstentions as 0.5 .
} 
statistic above the critical value (10\% maximal test size) indicates the rejection of weak instruments. Additionally, I also employ the Anderson canonical LR statistics for underidentification tests. The results in table 3 show that the instruments are strongly correlated with the instrumented endogenous variables, information flows and personal contacts, at conventional levels of significance in all specifications.

Second, the instruments cannot have independent effects on the dependent variable and can only explain y through a linkage with the endogenous independent variable. To test for the exclusion restrictions of the instruments, I employ the Sargan-Hansen test, which shows that the null-hypothesis of exogeneity cannot be rejected at conventional levels of significance.

Turning to the issue of human trafficking, to the best of my knowledge, there is no literature suggesting causal effects running from human trafficking to globalization. However, the model is designed to statistically minimize any suspicion of reverse-causality. For the cross-sectional estimations, I take the values of all the independent variables from the period prior to that in which the values consisting of the dependent variables were collected. For the panel analysis on human trafficking, I check for potential endogeneity by employing the Wald test of exogeneity to maximum likelihood variants. ${ }^{19}$

\section{Empirical Findings}

Table 2 shows the results for women's rights by employing ordered probit estimations, based on more than 3,000 observations from 146 countries in the last 28 years. In the estimations, the model includes the independent variables of interest with different combinations. First, the model includes the economic globalization variables only and a social globalization variable is then subsequently added. Columns (5), (10) and (15) show the results including all three social globalization variables, as well as civil liberty, a transmission mechanism ${ }^{20}$.

Regarding women's economic rights, trade openness positively affects women's economic rights at conventional levels of significance without controlling for social globalization, while the effect of FDI is largely insignificant. However, the positive effect of

\footnotetext{
${ }^{19}$ The Wald test is used to test whether the $\mathrm{x}$ variable, assumed to be endogenous, is really endogenous - i.e. $\mathrm{H}_{0}$ being that the correlation parameter rho is statistically different to zero in IV regressions. (Wooldridge 2002). The results show that one fails to reject the null hypothesis at conventional levels of significance in all of the specifications.

${ }^{20}$ However, including all the three variables is not the best specification given the high correlation amongst them (between 0.60 and 0.72 ).
} 
trade disappears when controlling for information flows and personal contacts. While these two indicators of social globalization have positive, significant effects on women's economic rights, cultural proximity is found to be insignificant. When all the five globalization indicators are included, the positive effect of information flows still remains (column 5), despite the high multi-collinearity between information flows and personal contacts $(r=0.72)$. This indicates the strong impact of social globalization. None of the two economic globalization variables turn out to be significant in these specifications.

Turning to the impact on women's social rights, social globalization, particularly through information flows and personal contacts, improves the level of women's social rights, while economic globalization is largely insignificant. Including all the five globalization variables, information flows persistently demonstrate a positive impact on women's social rights, while the personal contacts variable loses its significance (columns 10). Similar to women's economic rights, cultural proximity does not result in any significant effects on women's social rights ${ }^{21}$.

Surprisingly, neither economic nor social globalization affects women's political rights. None of the five globalization ind ic ators turns out to generate a significant effect. This is possibly driven by the fact that women's voting rights - the main component of the CIRI women's political rights indicator - are almost universally ensured and thus there are less cross-country and cross-time variations in this measurement. Still, globalization can be a determinant to a certain type of women's political representation, as Gray et al. (2006) find with female participation in the parliament. In fact, political rights are crucial to the improvement of other types of rights because these rights can enable women to advocate their economic and social rights (Apodaca 2001; Richards et al. 2001). Thus, an analysis on the effects of globalization on different components of women's political rights should be reserved for a future study.

The control variables behave mostly as expected. The lagged dependent variable has a high explanatory power and is significant at the $1 \%$ level in all the models, confirming the

\footnotetext{
${ }^{21}$ To highlight the significant effects of social globalization in a quantitative manner, I estimate the marginal effect (probability). The results in appendix 2 show that increasing personal contacts by one standard deviation increases the probability of achieving higher wo men's economic rights - score 2 and 3 - by $6 \%$ and $0.01 \%$ respectively, while decreasing the probability to be at the bottom level of wo men's economic rights, score 0 and 1 , by $0.2 \%$ and $6.4 \%$ respectively. A one standard deviation increase in information flows increases the probability of having a higher level of wo men's social rights - score 2 and 3 - by $4.7 \%$ and $0.02 \%$ respectively, while decreasing the probability to be score 0 and 1 by $0.7 \%$ and $4.7 \%$. It seems that the marginal effects of social globalization are sizeable in determining either relatively high women's rights (score 2) or relatively low women's rights (score 1).
} 
habituated and cultural nature of women's rights. While economic development - income does not generate a significant effect, political development -democracy and/or civil liberty positively affects women's rights. It is quite probable that economic development is not a direct determinant of women's rights, but rather has an indirect effect via institutional development. Having a higher proportion of Muslims in a country decreases women's social and political rights but the effect is insignificant for economic rights. Finally, being a member of the developed countries' club, the OECD, is positively associated with women's rights, indicating that the OECD's mandate to increase women's empowerment is translated into a positive outcome.

As expected, civil liberty demonstrates a strong effect on women's rights. As shown in appendix 1, social globalization promotes civil liberty and it is then transferred into improving women's rights. It seems that civil liberty - standing for civil association and the freedom of expression - is a direct linkage to the enhancement of women's rights compared to other institutional development, given that democracy loses its statistical significance when both variables are included $^{22}$. More interestingly, even after controlling for civil liberty, which can be a transmission mechanism from social globalization to women's rights, a social globalization indicator (information flows) still has significant, positive effects on women's economic and social rights. It implies that the effects of social globalization are stronger for women, going beyond the overall improvement in the civil liberty of all citizens, probably because women would mostly gain benefits from social changes rather than losing, compared to men who would experience a mixture of positive and negative effects from social globalization, potentially challenging the existing male-dominated social structures.

As presented in table 3, the reverse-causality effect is addressed by the instrumental variable approach (instrumenting the endogenous globalization variables as described in section 4.1). The results show that personal contacts increase women's economic rights and the effect is significant at the 5\% level. However, the positive effects of information flows on women's economic rights and personal contacts on women's social rights are not confirmed. Taking endogeneity into account, social globalization improves women's rights in two ways: women's economic rights via personal contacts and social rights via information flows (the latter is not instrumented given the results of the Granger-causality tests).

\footnotetext{
${ }^{22}$ For wo men's political rights, it is civil liberty that improves women's rights. Democracy does not turn out to have an impact regardless of the inclusion/exclusion of civil liberty.
} 
Finally, table 4 shows the results for human trafficking, a proxy of respect for marginalized foreign women. The results suggest that personal contacts tend to increase human trafficking inflows into a country, while other indicators of globalization do not have any significant effect, except cultural proximity in column $6^{23}$. This result seems to support a positive linkage between human trafficking and migration, which apparently increases personto-person contacts among different nationalities, as suggested in the literature (Mahmoud and Trebesch 2010). This result indicates that while social globalization is beneficial to domestic women's rights and status, it does not increase respect for foreign women without a legal standing in a country. In fact, globalization can even be detrimental to them as seen in the case of personal contacts. This argument can be supported with the finding that the level of women's rights in a country is unanimously insignificant to human trafficking inflows ${ }^{24}$. On the other hand, international exchanges of goods, services and capital turn out to be insignificant to human trafficking inflows.

In regards to control variables, higher controls on corruption reduce human trafficking inflows, while a higher level of income induces more human trafficking. The population size also increases human trafficking inflows, as expected. The results are consistent when employing different datasets on human trafficking flows as well as different estimation techniques, with the only exception being some minor changes in the significance levels of the control variables.

\section{Robustness of Findings}

To test for the robustness of the main findings, I employ several additional estimation methods. First, taking into account that changing people's perception and attitude towards women would require a substantial length of time, I lag the globalization indicators by up to five years. In fact, there is no consensus in the literature regarding the number of time lags required to generate change in perception and attitude. Thus I employ various time lags of the main independent variables (from one to five years). Replacing the contemporary indicators with the time lags does not alter the main finding. i.e. the positive effects of social

\footnotetext{
${ }^{23}$ Appendix 2 shows the marginal effects (probabilities) of personal contacts on human trafficking. Through an increase of one standard deviation in personal contact, the probability of a country having 'a medium level of flows', 'high flows' and 'very high flows' - i.e. score 3, 4 and 5 - increase by $25.5 \%, 15 \%$ and $2.1 \%$ respectively (although the effect for score 5 is not significant at conventional levels). At the same time, the probability of having low, very low or no (reported) flows - score 2, 1 and 0 - decrease by $15 \%, 19 \%$ and $8.5 \%$.

${ }^{24}$ When the model includes the wo men's economic rights variables in the estimation, instead of wo men's social rights, the result remains the same.
} 
globalization on women's economic and social rights still hold, while the impact of economic globalization disappear controlling for personal contacts and information flows.

Second, I employ liner estimations to address unobserved individual heterogeneity which was not captured in the ordered probit estimations due to incidental parameter problems (Wooldridge 2002). Following Neumayer and de Soysa (2007), I run OLS random effect estimations, given that the dependent variables do not have large sets of time variations and therefore fixed effect estimations may not be efficient reflecting a low bound of effects. The results support the main findings. In addition to the OLS random effect estimations, I average the data by five years and run regressions in order to further address the limited time variations in the dependent variable (women's rights). This approach allows me to estimate the model in a reduced manner without inflating the number of observations having little time variations on the left-hand side (Woodridge 2002). Averaging the dataset by five years does not change the inferences regarding social globalization.

Additionally, acknowledging that random effect regressions may result in biased estimations, I also implement fixed effect OLS estimations. For women's social rights, the positive effect of social globalization - information flows -is supported by the OLS two-way fixed effect estimations, while this positive effect is not confirmed for women's economic rights. On the one hand, this result may indicate that the time-invariant country characteristics largely explain the level of women's economic rights. On the other hand, the result may represent a low bound of the effect underestimating the impact of social globalization, as discussed above.

Furthermore, I replace the trade openness and FDI indicators with the KOF Economic Globalization Index, a composite indicator measuring actual flows and restrictions (Dreher 2006), in order to find whether the main findings are robust to the choice of globalization measurements. With the alternative indicator, the impact of social globalization is still significant and positive for women's economic and social rights, the result in line with the main findings.

Last, I run regressions with all possible combinations of control variables by employing an extreme bounds analysis (EBA) in order to see whether the results are robust to the choice of control variables ${ }^{25}$. The results confirm the positive effect of personal contacts

\footnotetext{
${ }^{25}$ For detailed information on the EBA method, please see Leamer (1983), Lev ine and Renelt (1992), and Sala-iMartin (1997).
} 
on women's economic rights and information flows on women's social rights. In contrast to this, the findings do not confirm the detrimental effect of personal contact on human trafficking, calling for a cautious interpretation of the main result.

\section{Conclusion}

In this paper I have analyzed how different dimensions of globalization affect various aspects of women's rights. As the theory predicts, it is social globalization that improves women's rights and empowers women. The impact of economic globalization - trade and FDI - on women's empowerment is muted when controlling for the effects of social globalization. The positive impact of social globalization seems to be logical given that improving women's rights in society is closely related to changes in perceptions, attitudes and ideas. However, this finding does not necessarily discount latent effects economic globalization may have via social globalization, which are conducive to women's empowerment. My finding rather suggests that economic globalization is not a sufficient condition for the enhancement of women's rights, requiring the spread of ideas and communications accompanied. How (and why) the different aspects of social globalization - information flows and personal contacts affect different dimensions of women's rights is still an open question, leaving room for further research.

Additionally, this analysis suggests that the beneficial effect of social globalization on local women's rights is not necessarily passed on to marginalized foreign women, which has been proxied by human trafficking inflows in this paper. As one can see, globalization does not reduce human trafficking inflows or the associated exploitation of women without a legal standing in a country, even increasing its incidence in some cases. It seems that the impact of globalization on women's rights is still limited, with its effects not yet having complete global penetration for cosmopolitan citizens. 


\section{Reference}

Akee, Randall, Arjun Bedi, Arnab K. Basu and Nancy H. Chau. (2010a) Transnational Trafficking, Law Enforcement and Victim Protection: A Middleman's Perspective, mimeo, Cornell University.

Akee, Randall, Arnab K. Basu and Nancy H. Chau and Melanie Khamis. (2010b) Ethnic Fragmentation, Conflict, Displaced Persons and Human Trafficking: An Empirical Analys is, IZA Discussion Paper Series. No. 5142.

Apodaca, Claire. (2001) Global Economic Patterns and Personal Integrity Rights After the Gold War. International Studies Quarterly 45(4): 587-602.

Beck, Nathaniel and Jonathan N. Katz. (1995) What to do (and not to do) with Time-Series Cross- Section Data. American Political Science Review 89(3): 634-647.

Berik, Günsel. (2000) Mature Export-led Growth and Gender Wage Inequality in Taiwan. Feminist Economics 6(3): 1-26.

Berik, Günsel, Yana van der Rodgers and Joseph E. Zveglich. (2004) International Trade and Gender Wage Discrimination: Evidence from East Asia. Review of Development Economics, 8, 2, 237-254.

Cağatay, Nilüfer and Korkuk Ertürk. (2004) Gender and Globalization: A Macroeconomic Perspective. International Labour Office Working Paper 19: Geneva.

Cingranelli, David and David Richards. (2008) The Cingranelli-Richards (CIRI) Human Rights Data Project Coding Manual.

Cho, Seo-Young. (2010) International Human Rights Treaty to Change Social Patterns - The Convention on the Elimination of All forms of Discrimination against Women. Cege Discussion Paper Series No.93. Georg-August University of Goettingen, Germany.

Cho, Seo-Young. (2012) Modeling for Determinants of Human Trafficking. Ibero-America Institute for Economic Research Discussion Paper No. 216, Georg-August-University of Goettingen, Germany.

Cho, Seo-Young, Axel Dreher and Eric Neumayer. (2012) Does Legalized Prostitution Increase Human Trafficking?, World Development (forthcoming).

Cho, Seo-Young, Axel Dreher and Eric Neumayer. (2011) The Spread of Anti-trafficking

Policies: Evidence from a New Index, CESifo Working Paper No. 3376, Munich.

Cho, Seo-Young and Krishna C. Vadlamannati. (2012) Compliance with the Anti-trafficking Protocol. European Journal of Political Economy, 28: 249-265.

Chow, Easter N-L. (2003) Gender Matters - Studying Globalization and Social Change 
in the 21st Century. International Sociology, 18, 3, 443-460.

Cragg, John, and Stephen Donald. (1993) Testing Identifiability and Specification in Instrumental Variable Models, Econometric Theory 9: 222-240.

De Soysa, Indra and Krishna C. Vadlamannati. (2011) Does Being Bound Together Suffocate, or Liberate? Testing the Effects of Economic, Social, and Political Globalization on Human Rights, 1981 - 2005. Kyklos 64(1): 20-53.

Dollar, David and Roberta Gatti. (1999) Gender Inequality, Income and Growth: Are Good Times Good for Women. World Bank Policy Research Report on Gender and Development Working Paper, No. 1.

Dreher, Axel. (2006) Does Globalization Affect Growth? Empirical Evidence from a new Index. Applied Economics 38, 10: 1091-1110.

Dreher, Axel, Martin Gassebner and Lars-H.R. Siemers. (2011) Globalization, Economic Freedom and Human Rights. Journal of Conflict Resolution, forthcoming.

Dreher Axel, Jan-Egbert Sturm. (2012) Do the IMF and the World Bank Influence Voting in the UN General Assembly? Public Choice 151(1): 363-397.

Elkins, Zachary and Beth Simmons. (2005) On Waves, Clusters, and Diffusion: A Conceptual Framework. Annals AAPSS: 598.

Encyclopedia Britannica Book. (2001) Share of Religions in Populations.

Freedom House. (2009) Civil Liberty Index.

Folster, Stefan and Magnus Henrekson. (2001) Growth Effects of Government Expenditure and Taxation in Rich Countries. European Economic Review 45(8): 1501-1520.

Fontana, Marzia and Adrian Wood. (2000) Modeling the Effect of Trade on Women, at Work and at Home. World Development, 28(7): 1173-1190.

Granger, Clive W. J. (1969) Investigating Causal Relations by Econometric Models and Cross- spectral methods. Econometrica 37: 424-438.

Gray, Mark M., Miki Caul Kittilson, and Wayne Sandholtz. (2006) Women and Globalization: A Study of 180 Countires, 1975-2000. International Organization 60(2): 293-333.

Hamilton, James Douglas. (1994) Time Series Analysis. Princeton University Press.

Jakobsson, Niklas and Andreas Kotsadam. (2011) The Law and Economics of international Sex Slavery: Prostitution Law and Trafficking for sexual Exploitation. European Journal of Law and Economics, DOI 10.1007/s10657-011-9232-0.

Kangaspunta, Kristiina. (2003) Mapping the Inhuman Trade: Preliminary Findings of the Database on Trafficking in Human Beings, Forum on Crime and Society 3(1 and 2): 81-103. 
Kaufmann, Daniel, Kraay, Aart and Massimo Mastruzzi. (2009) Governance Matters VIII: Aggregate and Individual Governance Indicators 1996-2008, Policy Research Working Paper Series 4978, The World Bank, Washington DC.

Long, Scott J. (1997) Regression Models for Categorical and Limited Dependent Variables. London: Sage.

Leamer, Edward E. (1983) Let's take the Con out of Econometrics. American Economic Review 73 (1): 31-43.

Levine, Ross and David Renelt. (1992) A Sensitivity Analysis of Cross-county Growth Regressions. American Economic Review 82 (4): 942-63.

Maddala, G.S and Shaowon Wu. (1999) A Comparative Study of Unit Root Tests with Panel Data and new Simple Test. Oxford Bulletin of Economic and Statistics 61: 631-652.

Mahmoud, Toman Omar, and Christoph Trebesch. (2010) The Economic Drivers of Human Trafficking: Micro-Evidence from Five Eastern European Countries, Journal of Comparative Economics 38(2): 173-188.

Marshall, Monty G. and Keith Jaggers. (2009) Polity IV Project: Political Regime Characteristics and Transitions, 1800-2009," Polity IV.

Morrison, Christian and Johannes P. Jütting. (2005) Women's Discrimination in Developing Countries: A New Dataset for Better Policies. World Development 33(7): 1065-1081.

Neumayer, Eric and Indra de Soysa. (2007) Globalization, Women's Economic Rights and Forced Labour. World Economy 30(10): 1510-1535

Neumayer, Eric and Indra de Soysa. (2011) Globalization and the Empowerment of Women: An Analysis of Spatial Dependence via Trade and Foreign Direct Investment. World Development 39(7): 1065-1075.

Ng, Serena and Pierre Perron. (1995) Unit Root Test in ARMA Models with Data-dependent Methods for the Selection of the Truncation Lag. Journal of the American Statistics Association 90: 268-281.

OECD. (2009) Social Institutions and Gender Index.

Oostendorp, Remco H. (2009) Globalization and the Gender Wage Gap, World Bank Economic Review 23:141-161

Poe, Steve, C. Neil Tate and Linda Keith. (1999) Repression of the Human Right to Personal Integrity Revisited: A Global Cross-National Study Covering the Years 1976-1993. International Studies Quarterly 43:291-313.

Potrafke, Niklas and Heinrich W. Ursprung. (2012) Globalization and Gender Equality in Developing Countries. European Journal of Political Economy, forthcoming. 
Richards, David and Ronald Gelleny. (2007) Women's Status and Economic Globalization. International Studies Quarterly 51:855-876.

Richards, David, Ronald Gelleny, and David H. Sacko. (2001) Money With a Mean Steak? Foreign Economic Penetration and Government Respect for Human Rights in Developing Countries. International Studies Quarterly 45(2):219-239.

Ross, Michael. (2008) Oil, Islam and Women. American Political Science Review 102(1): 107-123.

Rosenau, James N. (2003) Distant Proximities: Dynamics beyond Globalization. Princeton: Princeton University Press.

Sala-i-Martin, Xavier. (1997) I Just Ran Two Million Regressions. American Economic Review 87 (2): 178-183.

Sen, Amartya. (2001) Many Faces of Gender Inequality. Frontline. 18(22): 4-14.

Simmons, Beth and Zachary Elkins. (2004) The Globalization of Liberalization: Policy Diffusion in the International Political Economy. American Political Science Review 98(1): 171-189.

Simmons, Beth. (2009) Equality for Women: Education, Work and Reproductive Rights, Mobilizing for Human Rights: International Law in Domestic Politics. Cambridge University Press, NY.

Stock, James A., Jonathan H. Wright, and Motohiro Yogo. (2002) A Survey of Weak Instruments and Weak Identification in Generalized Method of Moments. Journal of Business and Economic Statistics. 20: 518-52

Sweeney, Shawna. (2006) Women's Human Rights: A Global, Comparative Analysis. PhD dissertation, State University of New York at Binghamton.

Sweeney, Shawna. (2007) Government Respect for Women's Economic Rights: A CrossNational Analysis, 1981-2003, in Economic Rights: Conceptual, Measurement, and Policy Issues (edited by Shareen Hertel). New York: Cambridge University Press.

Tzannatos, Zafiris. (1999) Women and Labor Market Changes in the Global Economy: Growth Helps, Inequalities Hurt and Public Policy Matters. World Development 27(3): 551-569.

Thacker, Strom. (1999) The High Politics of IMF Lending. World Politics. 52: 38-75.

Tyldum, Guri and Anette Brunovskis. (2005) Describing the Unobserved: Methodological Challenges in Empirical Studies on Human Trafficking in Data and Research on Human Trafficking: A Global Survey, edited by Frank Laczko, International Organizations for Migration, Geneva. 
United States Department of State. (2001-2009) Trafficking in Persons Report, Office of the Undersecretary for Global Affairs, Washington DC.

United Nations Population Fund. (2008) International Migration Data.

United Nations Office on Drugs and Crime (UNODC). (2006) Trafficking in Persons, Global Patterns.

Wooldridge, Jeffrey. (2002) Econometric Analysis of Cross Section and Panel Data. MIT Press.

World Bank. (2009) World Development Indicator. 


\section{Figure 1. UNODC Index on Human Trafficking Inflows}

(Distribution of Ranking by Countries, 1996-2003, 161 countries)

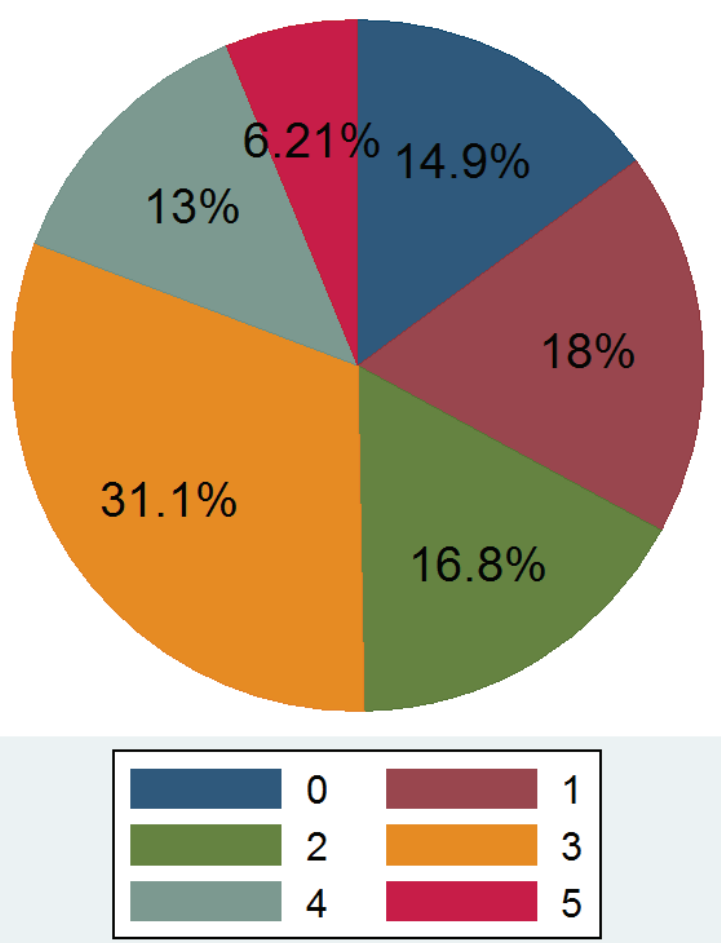

score 0: no flows; score 1: very low; score 2: low; score 3: medium; score 4: high; score 5: very high flows 
Table 1. Granger Causality Tests, 1981-2008, 146 countries

\begin{tabular}{|c|c|c|}
\hline & $\mathrm{Y}=$ Trade $; \mathrm{X}=$ Wecon & $\mathrm{Y}=$ Wecon; $\mathrm{X}=$ Trade \\
\hline F-statistics & 0.09 & 8.54 \\
\hline \multirow[t]{2}{*}{ P-value for Joint Significance } & 0.77 & 0.004 \\
\hline & $\mathrm{Y}=\mathrm{FDI} ; \mathrm{X}=$ Wecon & $\mathrm{Y}=$ Wecon; $\mathrm{X}=$ FDI \\
\hline F-statistics & 2.11 & 13.15 \\
\hline \multirow[t]{2}{*}{ P-value for Joint Significance } & 0.15 & 0.0003 \\
\hline & $\mathrm{Y}=$ Information flows; $\mathrm{X}=$ Wecon & $\mathrm{Y}=$ Wecon; $\mathrm{X}=$ =Information flows \\
\hline F-statistics & 4.96 & 74.28 \\
\hline \multirow[t]{2}{*}{ P-value for Joint Significance } & 0.03 & 0.00 \\
\hline & $\mathrm{Y}=$ Personal contact; $\mathrm{X}=$ Wecon & $\mathrm{Y}=\mathrm{Wecon} ; \mathrm{X}=$ Personal contact \\
\hline \multirow{3}{*}{$\begin{array}{c}\text { F-statistics } \\
\text { P-value for Joint Significance }\end{array}$} & 3.07 & 30.72 \\
\hline & 0.08 & 0.00 \\
\hline & $\mathrm{Y}=$ Cultural proximity $; \mathrm{X}=$ Wecon & $\mathrm{Y}=$ Wecon; $\mathrm{X}=$ Cultural proximity \\
\hline F-statistics & 1.82 & 48.99 \\
\hline \multirow[t]{2}{*}{ P-value for Joint Significance } & 0.18 & 0.00 \\
\hline & $\mathrm{Y}=$ Trade; $\mathrm{X}=$ Wosoc & $\mathrm{Y}=$ Wosoc; $\mathrm{X}=$ Trade \\
\hline F-statistics & 1.33 & 1.40 \\
\hline \multirow[t]{2}{*}{ P-value for Joint Significance } & 0.25 & 0.24 \\
\hline & $\mathrm{Y}=\mathrm{FDI} ; \mathrm{X}=$ Wosoc & $\mathrm{Y}=$ Wosoc; $\mathrm{X}=$ FDI \\
\hline F-statistics & 0.66 & 11.60 \\
\hline \multirow[t]{2}{*}{ P-value for Joint Significance } & 0.42 & 0.001 \\
\hline & $\mathrm{Y}=$ Information Flows; $\mathrm{X}=$ Wosoc & $\mathrm{Y}=$ Wosoc; $\mathrm{X}=$ =Information flows \\
\hline \multirow{3}{*}{$\begin{array}{c}\text { F-statistics } \\
\text { P-value for Joint Significance }\end{array}$} & 0.70 & 28.48 \\
\hline & 0.40 & 0.00 \\
\hline & $\mathrm{Y}=$ Personal contact $; \mathrm{X}=$ Wosoc & $\mathrm{Y}=$ Wosoc; $\mathrm{X}=$ Personal contact \\
\hline F-statistics & 5.42 & 10.05 \\
\hline \multirow[t]{2}{*}{ P-value for Joint Significance } & 0.02 & 0.002 \\
\hline & $\mathrm{Y}=$ Cultural proximity $; \mathrm{X}=$ Wosoc & $\mathrm{Y}=$ Wosoc; $\mathrm{X}=$ Cultural proximity \\
\hline & 0.27 & 27.17 \\
\hline \multirow{2}{*}{ P-value for Joint Significance } & 0.61 & 0.000 \\
\hline & $\mathrm{Y}=$ Trade; $\mathrm{X}=$ Wopol & $\mathrm{Y}=$ Wopol; $\mathrm{X}=$ Trade \\
\hline \multirow{3}{*}{$\begin{array}{c}\text { F-statistics } \\
\text { P-value for Joint Significance }\end{array}$} & 0.82 & 0.00 \\
\hline & 0.37 & 0.98 \\
\hline & $\mathrm{Y}=$ FDI; X = Wopol & $\mathrm{Y}=$ Wopol; $\mathrm{X}=$ FDI \\
\hline F-statistics & 0.14 & 2.77 \\
\hline \multirow[t]{2}{*}{ P-value for Joint Significance } & 0.71 & 0.10 \\
\hline & $\mathrm{Y}=$ Information Flows; $\mathrm{X}=$ Wopol & $\mathrm{Y}=$ Wopol; $\mathrm{X}=$ =Information flows \\
\hline \multirow{3}{*}{$\begin{array}{c}\text { F-statistics } \\
\text { P-value for Joint Significance }\end{array}$} & 0.07 & 18.72 \\
\hline & 0.79 & 0.00 \\
\hline & $\mathrm{Y}=$ Personal contact $; \mathrm{X}=$ Wopol & $\mathrm{Y}=$ Wopol; $\mathrm{X}=$ Personal contact \\
\hline \multirow{3}{*}{$\begin{array}{c}\text { F-statistics } \\
\text { P-value for Joint Significance }\end{array}$} & 0.95 & 6.70 \\
\hline & 0.33 & 0.01 \\
\hline & $\mathrm{Y}=$ Cultural proximity $; \mathrm{X}=$ Wopol & $\mathrm{Y}=$ Wopol; $\mathrm{X}=$ Cultural proximity \\
\hline $\begin{array}{c}\text { F-statistics } \\
\text { P-value for Joint Significance }\end{array}$ & $\begin{array}{l}0.17 \\
0.68\end{array}$ & $\begin{array}{l}21.05 \\
0.000\end{array}$ \\
\hline
\end{tabular}

Note: The table reports p-values for F-statistics (joint significance) using one lag. One year lagged dependent variables and fixed effects are included. Wecon: women's economic rights; Wosoc: women's social rights; and Wopol: women's political rights. 


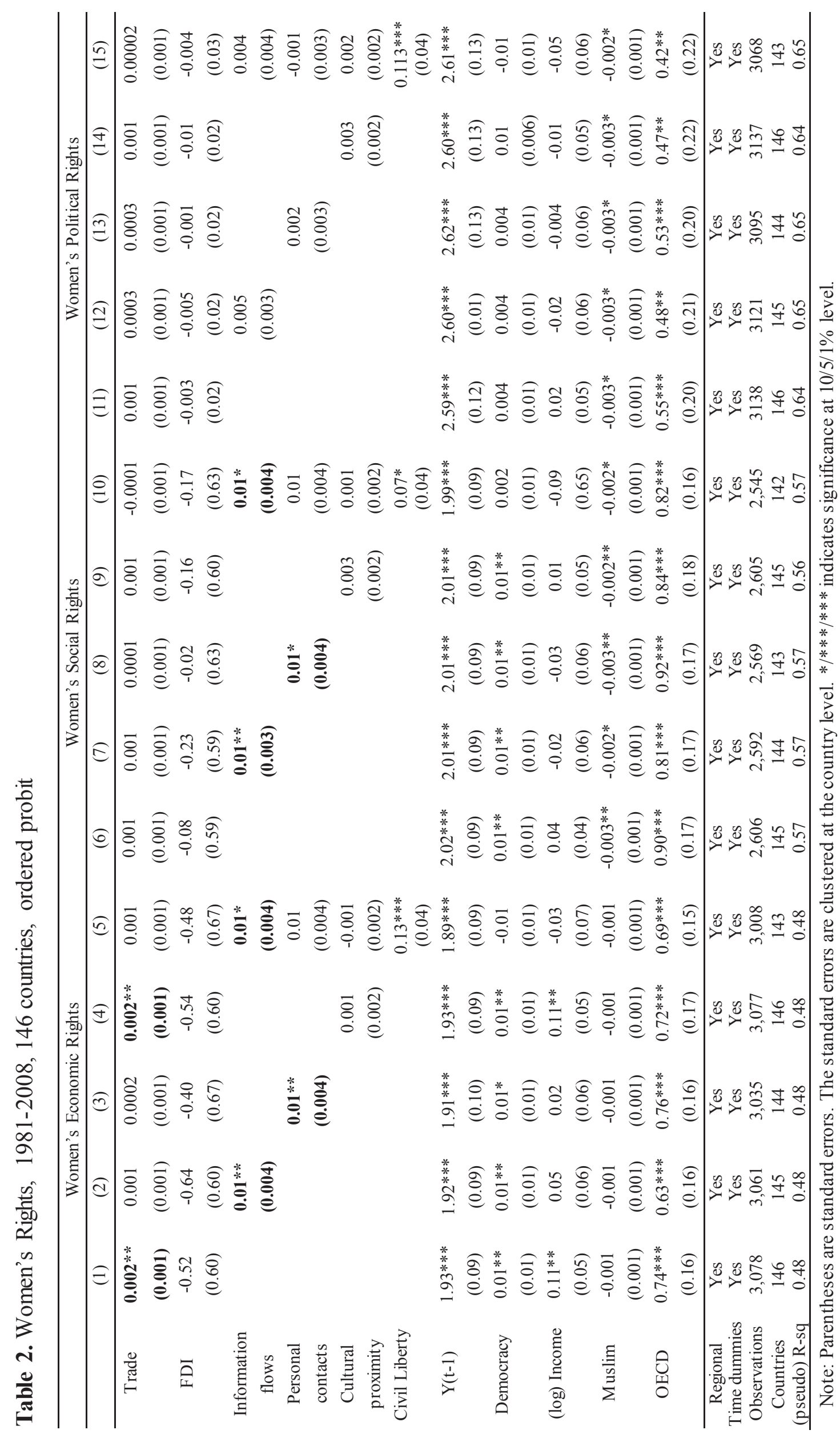




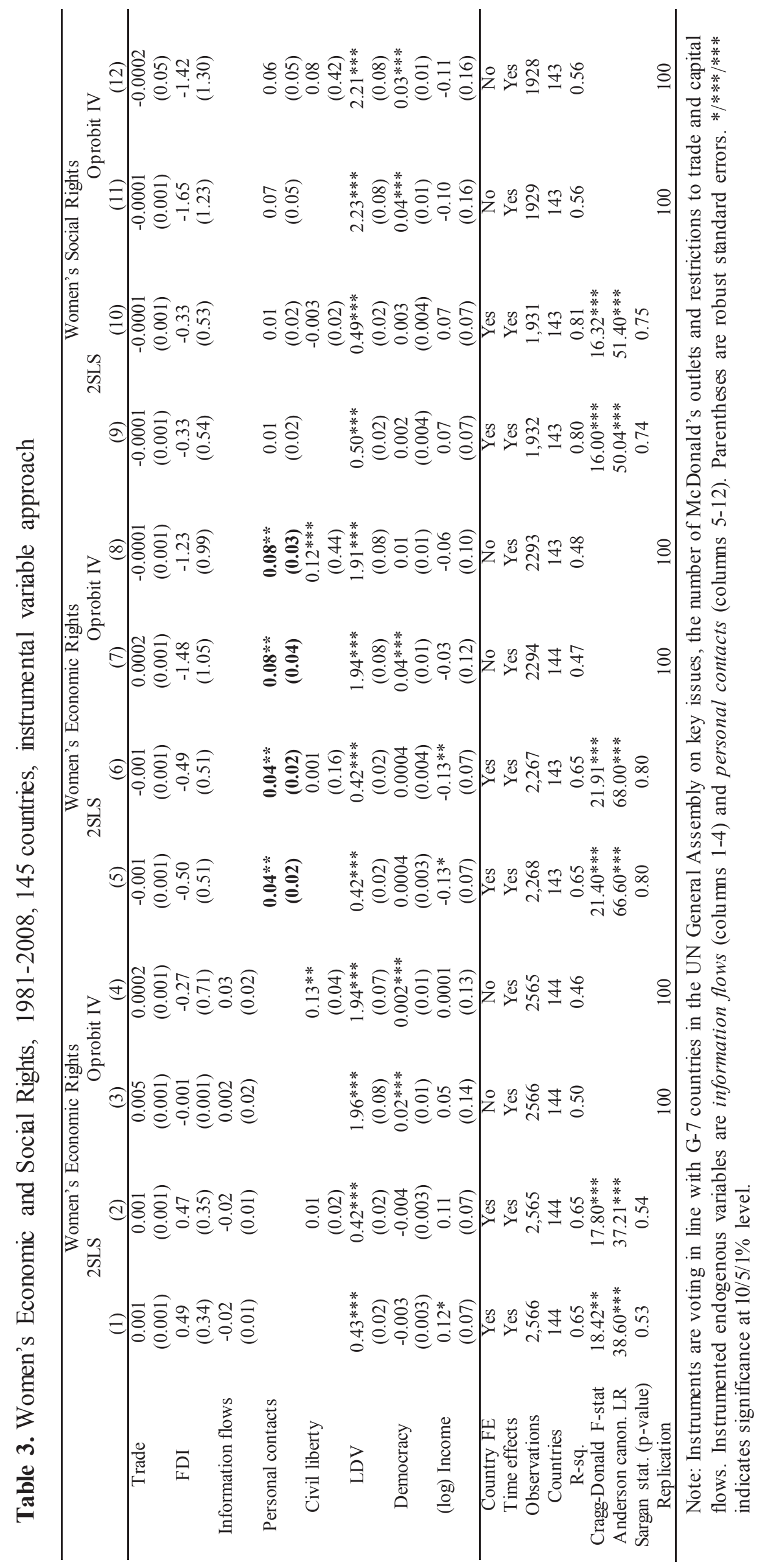




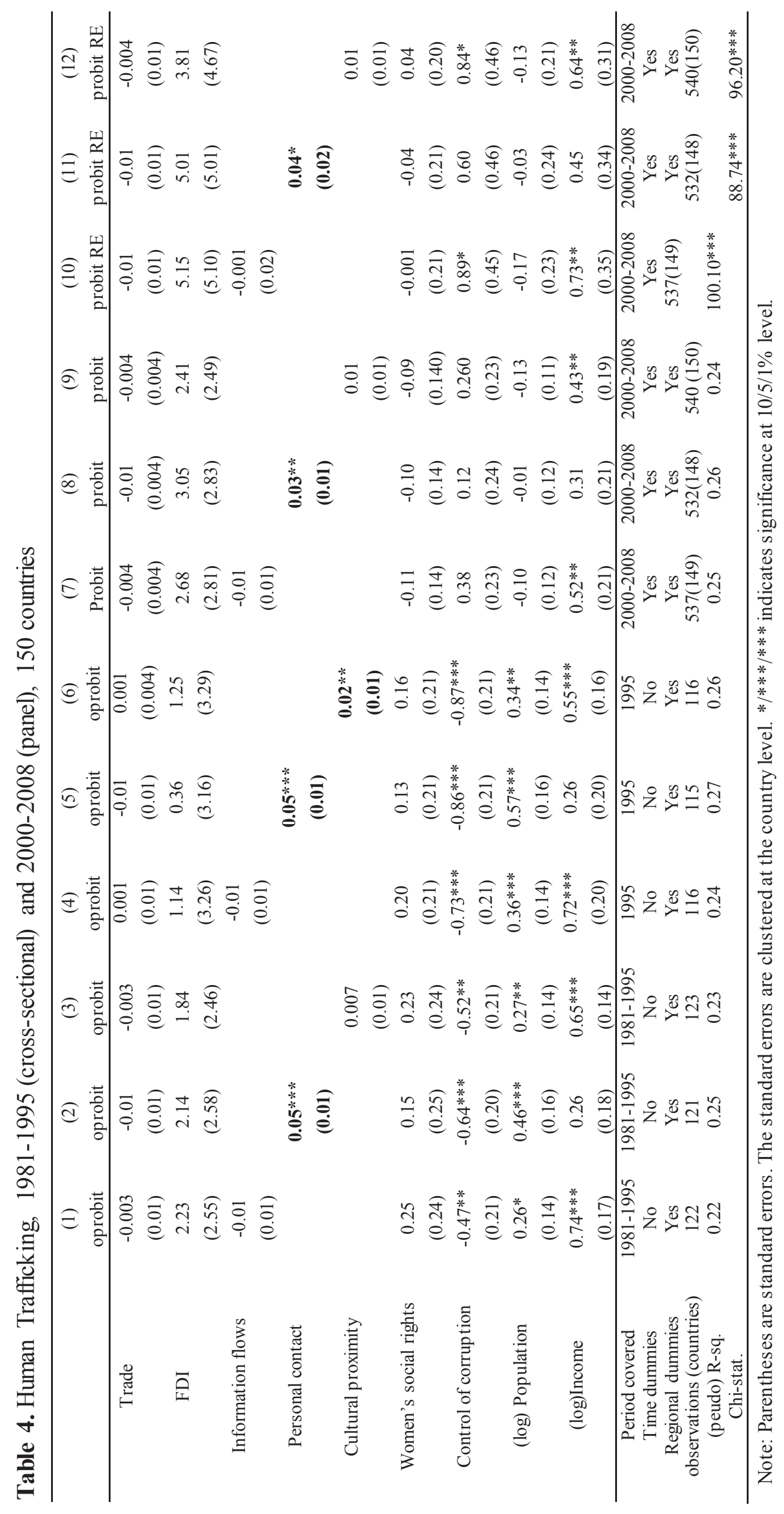


Appendix 1. Transmission Mechanism: Globalization and Civil Liberty

\begin{tabular}{ccc}
\hline & \multicolumn{2}{c}{$\begin{array}{c}\text { Civil Liberty } \\
\text { Ordered probit (1981-2008) }\end{array}$} \\
\hline Economic globalization & 0.01 & -0.003 \\
& $(0.01)$ & $(0.01)$ \\
Social globalization & $0.02 *$ & $0.03 * * *$ \\
& $(0.01)$ & $(0.01)$ \\
Democracy & & $0.19 * * *$ \\
& & $(0.03)$ \\
(log) Income & $0.31 * * *$ & $0.26^{* * *}$ \\
& $(0.09)$ & $(0.10)$ \\
OECD & $1.25 * * *$ & 0.09 \\
& $(0.45)$ & $(0.43)$ \\
Muslim & -0.01 & 0.0003 \\
& $(0.003)$ & $(0.003)$ \\
\hline Country fixed-effects & Regional dummies & Regional dummies \\
Time effects & Yes & Yes \\
Observations & 3363 & 3204 \\
Countries & 137 & 130 \\
(peudo) R-sq & 0.28 & 0.40 \\
\hline Note: Parenthes are standard errors. The standard errors are clustered at the country level. */**/***indicates
\end{tabular}

Note: Parentheses are standard errors. The standard errors are clustered at the country level. $* / * * * / * * *$ indicates significance at $10 / 5 / 1 \%$ level. 
Appendix 2. Marginal Effects

Women's Economic Rights

\begin{tabular}{lccccc}
\hline Index value & 0 & 1 & 2 & 3 & $\mathrm{E}[\mathrm{Y}]$ \\
\hline Sample & 0.07 & 0.58 & 0.33 & 0.03 & 1.33 \\
frequency & 0.004 & 0.72 & 0.28 & 0.0002 & 1.27 \\
$\begin{array}{l}\text { Probability at } \\
\text { means }\end{array}$ & & & & \\
Personal & -0.0001 & -0.003 & 0.003 & 0.0001 & 0.003 \\
contact & 0.04 & 0.02 & 0.02 & 0.09 & 0.02 \\
p-value & & & & & \\
\hline
\end{tabular}

Women's Social Rights

\begin{tabular}{lccccc}
\hline Index value & 0 & 1 & 2 & 3 & $\mathrm{E}[\mathrm{Y}]$ \\
\hline Sample & 0.16 & 0.53 & 0.21 & 0.09 & 1.23 \\
frequency & 0.01 & 0.82 & 0.17 & 0.0003 & 1.16 \\
$\begin{array}{l}\text { Probability at } \\
\text { means }\end{array}$ & & & & & \\
Information & -0.0003 & -0.002 & 0.002 & 0.0001 & 0.002 \\
flows & 0.03 & 0.02 & 0.02 & 0.12 & 0.02 \\
p-value & & & & & \\
\hline
\end{tabular}

Human Trafficking

\begin{tabular}{lccccccc}
\hline Index value & 0 & 1 & 2 & 3 & 4 & 5 & $\mathrm{E}[\mathrm{Y}]$ \\
\hline Sample frq. & 0.12 & 0.17 & 0.17 & 0.33 & 0.13 & 0.07 & 2.40 \\
$\begin{array}{l}\text { Prob. at } \\
\text { means }\end{array}$ & 0.03 & 0.13 & 0.23 & 0.52 & 0.08 & 0.01 & 2.50 \\
$\begin{array}{l}\text { Personal } \\
\text { contact }\end{array}$ & -0.004 & -0.01 & -0.01 & 0.01 & 0.01 & 0.001 & 0.05 \\
p-value & 0.01 & 0.003 & 0.004 & 0.01 & 0.001 & 0.17 & 0.00 \\
\hline
\end{tabular}

Note: The table reports the marginal effects corresponding to tables 2 and 4 . The row 'sample frequency' reports the observed frequency in the sample, while 'p robability at means' yields the probability for observing a given index value according to the estimated model. 